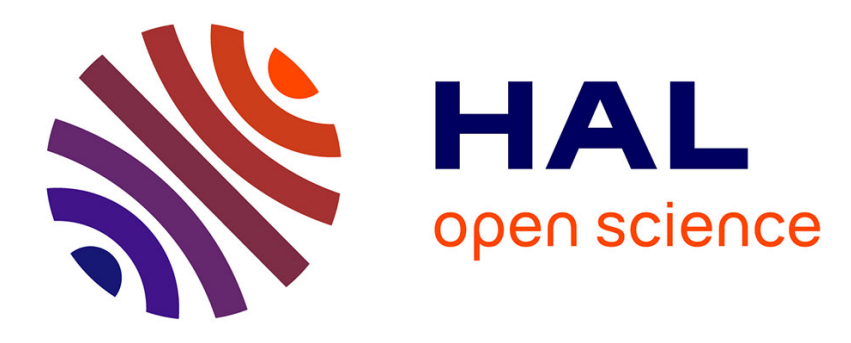

\title{
Strength evaluation of sintered ceramics by dynamic crack path model
}

T. Shioya, H. Ohnishi, K. Satoh

\section{To cite this version:}

T. Shioya, H. Ohnishi, K. Satoh. Strength evaluation of sintered ceramics by dynamic crack path model. Journal de Physique IV Proceedings, 1994, 04 (C8), pp.C8-701-C8-706. 10.1051/jp4:19948107 . jpa-00253348

\section{HAL Id: jpa-00253348 https://hal.science/jpa-00253348}

Submitted on 1 Jan 1994

HAL is a multi-disciplinary open access archive for the deposit and dissemination of scientific research documents, whether they are published or not. The documents may come from teaching and research institutions in France or abroad, or from public or private research centers.
L'archive ouverte pluridisciplinaire HAL, est destinée au dépôt et à la diffusion de documents scientifiques de niveau recherche, publiés ou non, émanant des établissements d'enseignement et de recherche français ou étrangers, des laboratoires publics ou privés. 


\title{
Strength evaluation of sintered ceramics by dynamic crack path model
}

\author{
T. Shioya, H. Ohnishi and K. Satoh \\ Department of Aeronautics and Astronautics, University of Tokyo, 7-3-1 Hongo, Bunkyo-ku, Tokyo I13, \\ Japan
}

Comme méthode d'estimation de la solidité des matériaux céramiques, l'emploi d'un modèle simplifié de la fissure propagation est proposé. L'analyse consiste à déterminer si la trajectoire d'une fissure s'avance entre les grains (inter-grain) ou traverse le grain (trans-grain). Le critérium de sélection de la trajectoire dépend de l'énergie libérée dans l'ensemble du système au cours de l'extension de la fissure. La colonne hexagonale est choisie pour représenter la forme du grain, qui caractérise la structure cristalline de la silicone azotée. Les trajectoires sont indiquées et la proportion entre les deux énergies -formation de la surface inter-grain et trans-grain - est mise en rapport avec la proportion entre les étendues inter-grain et trans-grain dans la surface fracturée, afin d'estimer facilement la solidité des matériaux ceramiques.

A method of estimating the inter-grain strength of sintered ceramics is proposed by means of a simplified analytical crack-propagation model. The analysis is focused on the determination of inter- or trans-granular fracture path. The criterion of crackpath selection is based on the total released energy rate of the system on the crack extension. The hexagonal column is chosen as the grain shape featuring a silicon nitride crystal structure. The crack-propagation paths are shown, and the ratio of surface-formation-energies on inter- and on trans-granular paths is related with the inter-/trans-granular area ratio on the fracture surface, so as to estimate the strength of sintered ceramics.

\section{INTRODUCTION}

Ceramics have advantage of light-weightness and high heat-resistance compared with the conventional metallic materials, so that they are expected as future structural materials in the field where such properties are highly required. However, on the other hand, ceramics have disadvantage of brittleness which poses the difficult problem for practical use. Many studies have been made on the brittle fracture of ceramics. Many of them are devoted to the measurement of fracture toughness, observation of fracture surfaces, and etc. However the micro mechanism of fracture itself has not been analyzed extensively.

In this paper, the micro mechanism of brittle crack propagation in ceramics is analyzed with respect to crack path selection. The past studies on crack paths have been mainly based on macroscopic view point (continuum mechanics), and their criteria are either based on the singularity at the crack tip or based on the energy in the whole system. A hypothesis on the extension direction for a stationary 
crack in the mixture of mode I and II by Erdogan and $\mathrm{Sih}^{(1)(2)}$ is an example of the former, and one of the latter examples is an analysis of dynamic crack propagation in an infinite plate by the usc of Lagrange's equation by Shioya and Fujimoto. ${ }^{(3)(4)}$ In the present paper the study is in the latter category, however, it is based on the microscopic view point considering the structure of materials.

The microscopic feature of fracture in polycrystalline ceramics such as sintered ceramics is classified into two modes. One is the mode in which the crack propagates along grain boundaries (inter-granular fracture mode), and in the other mode, it propagates along a certain plane such as one of the cleavage planes in the grain (trans-granular fracture mode). Actual fracture surfaces are mixture of the two modes. The larger the proportion of inter-granular fracture is, the weaker the grain boundary becomes. Generally the strength of grain itself is relatively high and stable, while the grain boundary strength depends very much on the sintering process, additives, temperature and so on. The strengthening of grain boundaries is, thereby, considered to be one of the most important factor in the development of high-strength ceramics, and the establishment of evaluation method for the strength of grain boundaries quantitatively is greatly required for practical use.

In this paper, an analysis is shown based on microscopic (inter-/trans-granular) model of a brittle crack propagating in a polycrystal. In the actual numerical model, a hexagonal crystal structure is assumed for the grain featuring a sintered silicon nitride and Monte-Calro simulation is utilized for the distribution of grains which can meet the crack path. The result is shown for the relationship between the inter-/trans-granular surface-formation-energy ratio and the fracture-surface ratio, giving a method of evaluating the strength of grain boundary from the fractography analysis.

\section{MICROSCOPIC CRACK-PROPAGATION MODEL}

A crack is supposed to propagate in an infinite plate of polycrystalline ceramics under uniform tensile stress $\sigma$. Figure 1 illustrates the crack path at the encounter of grain boundary where the notations are defined; $Y$-axis in the direction of $\sigma, Y$-axis vertical to $\sigma$ (the direction of the crack propagating macroscopically at mode I). The crack takes a particular path in the grain or along the grain boundary with the angle of $\theta$ from $X$-axis. $\theta_{\mathrm{i}}$ is the angle when the crack propagates along a grain boundary, and $\theta_{t}$ is that along a cleavage plane in the grain. $\gamma_{i}$ is the surfaceformation energy per unit boundary length, and $\gamma_{t}$ is that along a cleavage plane in the grain. Generally $\gamma_{l}$ is larger than $\gamma_{\mathrm{j}}$. As the energy consideration on the crack extension, Griffith's theory ${ }^{(\mathcal{S})}$ is famous for establishing the basis of fracture mechanics. In his model, the crack is supposed to expand without changing the

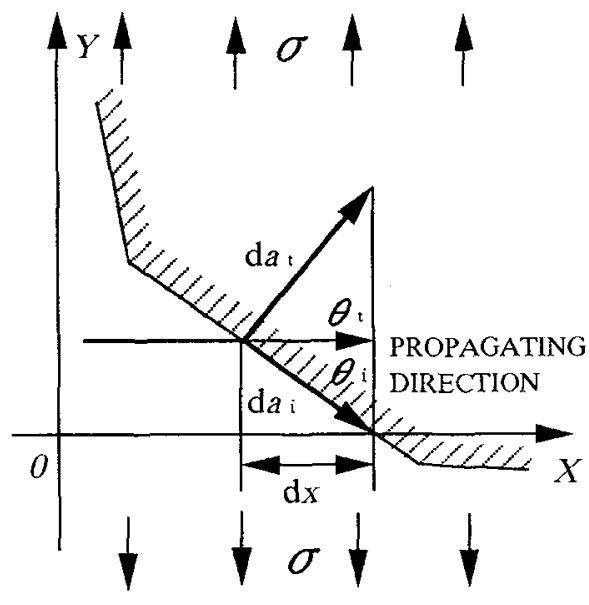

Fig.1 Crack path model at the encounter of grain boundary under uniform tensile stress o

direction. However, in the present model, the energy change and the crack propagation is considered in the case when the crack propagates with kinky turning. After turning, the crack is supposed to expand small length $\mathrm{d} a$ with the angle of $\sigma$ from $X$-axis. The elastic field of kinked crack is complicated with the mixture of mode I and mode II. However, as the crack can be regarded to propagate macroscopically at mode $I$ in this model, the elastic energy release $\mathrm{d} U_{\mathrm{a}}$ is approximated to that of mode I with propagating length $\mathrm{d} x(=\mathrm{d} a \cos \theta)$. that is 


$$
\mathrm{d} U_{\mathrm{a}}=\frac{2 \pi \sigma^{2} c \mathrm{~d} x}{\mathrm{E}}
$$

At the above equation, $c$ is the total length of the crack, and $E$ is the Young's modulus. On the other hand, the surface-formation-energy $\mathrm{d} U_{\mathrm{g}}$ by the formation of crack surface da is

$$
\mathrm{d} U_{\mathrm{g}}=\gamma \mathrm{d} a=\gamma \frac{\mathrm{d} x}{\cos \theta} .
$$

The condition of crack extension is that $\mathrm{d} U_{\mathrm{g}}$ reaches $\mathrm{d} U_{\mathrm{a}}$. If there are more than one candidate paths, it is natural to choose one which gives the lowest $\mathrm{d} U_{\mathrm{g}}$ for the same $\mathrm{d} U_{\mathrm{a}}$. If the crack meets a grain boundary and may turn its path with the angle of either $\theta_{j}$ (inter-granular path) or $\theta_{t}$ (trans-granular path), the condition that the former path is taken is

$$
\frac{\cos \theta_{t}}{\cos \theta_{i}}<\frac{\gamma_{t}}{\gamma_{i}} \text {. }
$$

The condition of the latter path is

$$
\frac{\cos \theta_{t}}{\cos \theta_{i}}>\frac{\gamma_{t}}{\gamma_{i}}
$$

The above simple criterion of crack path selection is employed in the following simulation procedure.

\section{PROCESS OF SIMULATION}

In the present analysis, a silicon nitride type structure is chosen as the material. A silicon nitride crystal has three structures, amorphous type, $\alpha$-type and $\beta$-type. In the simulation, crystal structure in the grains is assumed to be $\beta$-type. $\beta$-type structure has cleavage planes along which the crack can propagate. The shape of the grains is assumed to be similar to the crystal structure itself (hexagonal column) with the aspect ratio of 3 . The space other than the grains is assumed to be filled with the amorphous phase material. In the simulation procedure, grains are distributed 3dimensionally along the possible crack path, however, the crack path is considered only on the cross section plane (i.e., $X-Y$ plane) in order to avoid the complexity. The method of distributing the grains is that each time the

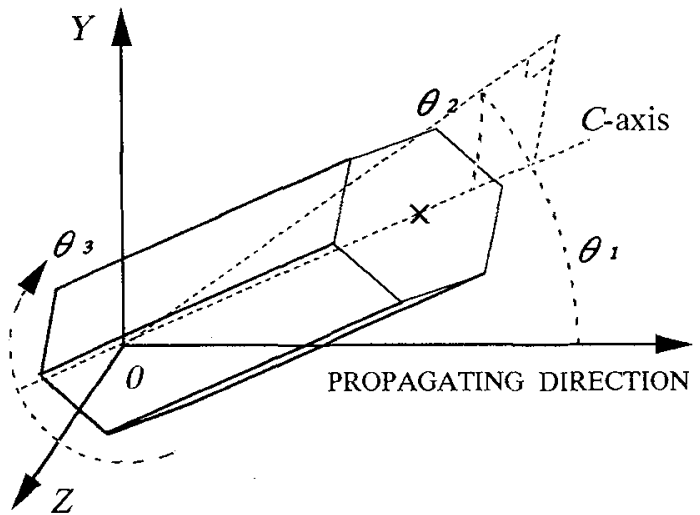

Fig.2 Orientation of grain $\left(\theta_{1}:\right.$ angle from $X$-axis in $X-Y$ plane, $\theta_{2}:$ angle from $X-Y$ plane, $\theta_{3}$ : rotational angle around $C$-axis)

crack passes through several grains, next several grains are distributed. Detailed procedure is as follows. The center of grains on the $X-Y$ plane and their crystal directions $\left(C\right.$-axes, $\theta_{1}:$ the angle from $X$-axis in $X-Y$ plane, $\theta_{2}$ : the angle from $X-Y$ plane, $\theta_{3}$ : the rotational angle around $C$-axis : Fig.2) are chosen randomly in a specified unit area in front of the crack, and the grains are grown step by step until they touch each other. The configuration of the grains ahead of the crack being specified by the above procedure, the crack is extended stepwise. Each step is from a crack kink point to the next kink point, i.e., at the end of each step, the crack meets a grain boundary where the 
criterion of path selection is examined whether the fracture is inter-granular or trans-granular by equations (3) and (4). $\gamma_{i}$ and $\gamma_{t}$ are assumed to be constant independent of the crack velocity. During the propagation in the amorphous phase, the crack path is supposed to be parallel to the macroscopic propagating direction, i.e., $X$-axis. The resultant configuration of grain distribution and crack path obtained by the above method is illustrated in an example shown in Fig.3. Figure 4 shows the flow chart of the simulation.

The surface-formation energies $\gamma_{\mathrm{i}}$ and $\gamma_{1}$ in inter-granular and trans-granular paths, depend strongly on the temperature, the sintering process and so on. As shown above, the value $\gamma_{j} / \gamma_{1}$ concerns directly to the fracture process in the model and it is employed as the variable in the simulation.

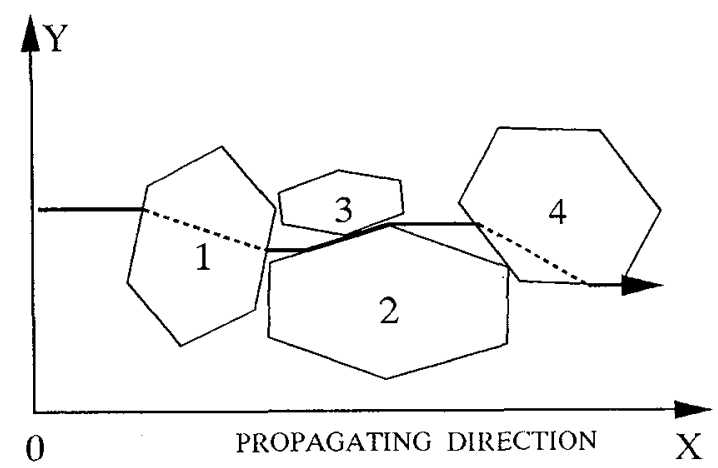

Fig.3 Example of crack path and grain distribution on $X-Y$ plane

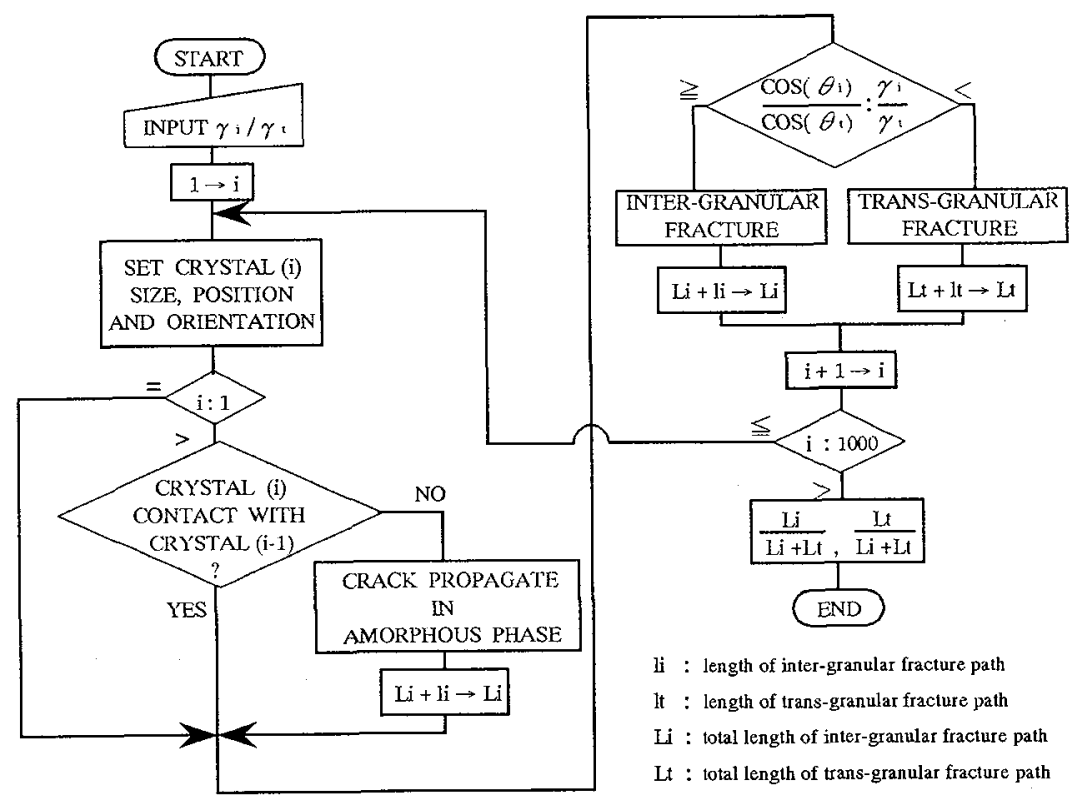

Fig.4 Flow chart of the simulation

\section{RESULT OF SIMULATION}

Figure 5 shows examples of calculated crack paths for various values of $\gamma_{j} / \gamma_{i}$. In this figure, solid lines and dotted lines show the parts of inter-granular fracture and trans-granular fracture, respectively. The ratio of these length corresponds to the fracture surface ratio on the actual fracture surface. The figure shows the tendency that the larger the value of $\gamma_{j} / \gamma_{1}$ is, the larger the inter-granular fracture surface ratio is. This relationship is obtained in a graphical form by performing numbers of simulations and is exhibited in Fig.6. In order to obtain accuracy, one thousand grains are distributed along the crack path in the simulation. 


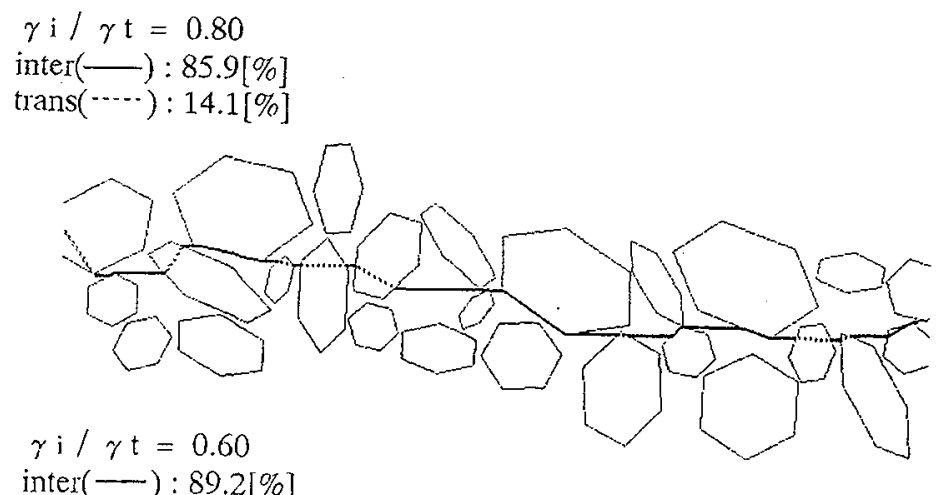

inter (-) : 89.2[\%]

$\operatorname{trans}(\cdots \cdot): 10.8[\%]$

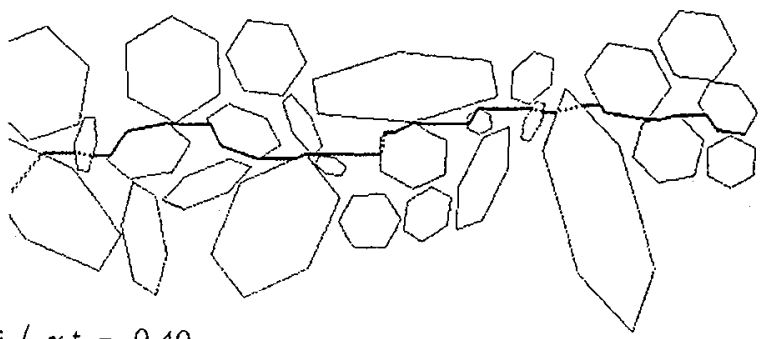

$\gamma \mathrm{i} / \gamma \mathrm{t}=0.40$

inter $(\longrightarrow): 93.2[\%]$

$\operatorname{trans}(\cdots \cdot): 6.8[\%]$

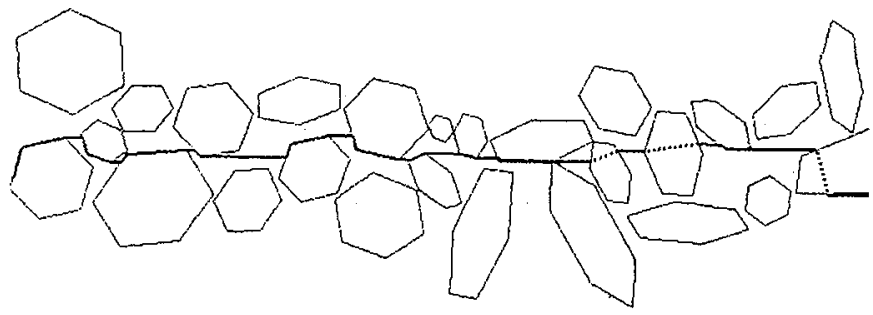

$\gamma \mathrm{i} / \gamma \mathrm{t}=0.20$

inter $(-): 100.0[\%]$

$\operatorname{trans}(\cdots): 0.0[\%]$

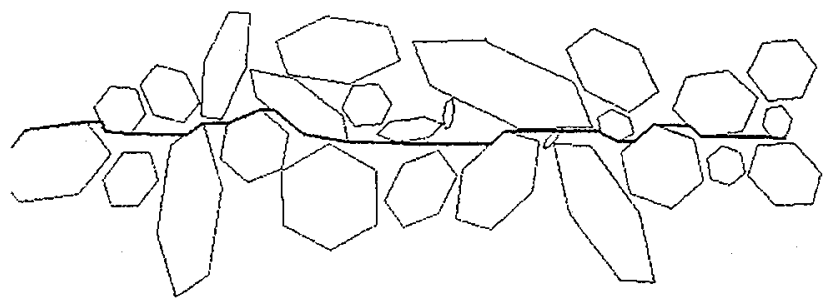

Fig.5 Examples of caluculated crack path (inter-/trans-granular fiacture) for various values of $y_{i} / \gamma_{\text {, }}$ 


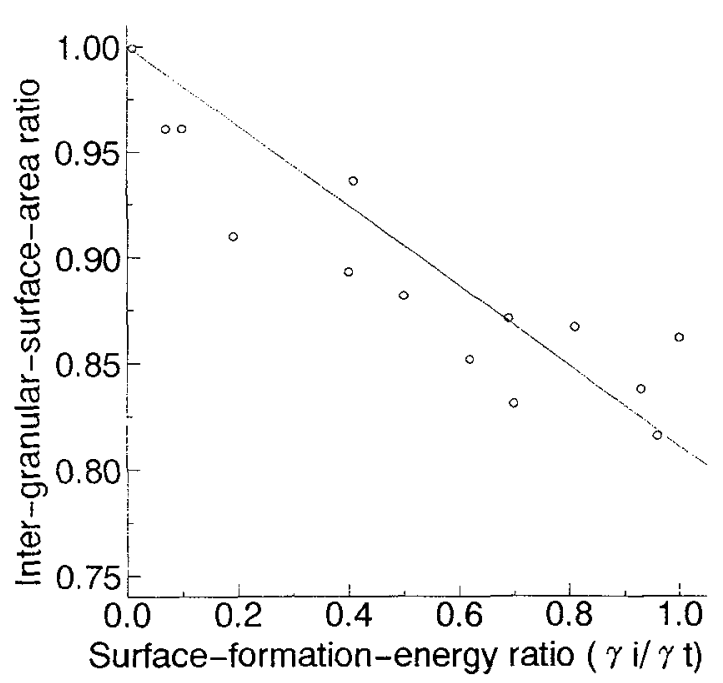

Fig.6 Inter-granular surface area ratio on the fractured surface versus surface-fomation-energy ratio (in case : hexagonal column grains with amorphous grain boundaries)



Fig.7 Inter-granular surface area ratio on the fractured surface versus surface-formation-energy ratio (in case : tetrahedron grains without amorphous phase)

\section{DISCUSSIONS AND CONCLUSION}

A method of obtaining the ratio of surface-formation energies $\gamma_{i} / \gamma_{1}$ is newly proposed by crack propagation simulations based on an energy release theory. Since the surface-formation encrgy is considered to be almost constant, the knowledge of ratio $\gamma_{i} / \gamma_{t}$ leads to the evaluation of grain boundary strength, i.e., the sintering procedure, additives, and etc can be evaluated. $\gamma_{i} / \gamma_{1}$ is related to the proportion of inter-granular-area on the fractured surface. It has approximately linear decrement relation with the area ratio on the fractured surface. The shape of grains is assumed to be hexagonal column in the analysis. The actual configuration of grains may vary depending on the material, so that the simulation should be executed for each case. For example, Fig.7 shows the result for the simulation in which the crystal structure is a tetrahedron with the cleavage plains of its 4 face planes. Amorphous phase is omitted in the calculation. In this case, the decrease rate of $\gamma_{\mathrm{f}} / \gamma_{\mathrm{t}}$ is more rapid than in the case of Fig.6, however, general tendency remains unchanged. In the present analysis, the surface-formation energy is assumed to be independent of the crack velocity. These effects can be included in the simulation if the rate dependency characteristic is known.

\section{References}

[1] Erdogan,F., Sih,G.C., Trans. ASME, J.Basic. Engineering, 85(1963), 519.

[2] Sih,G.C., in Mechanics of Fracture, Vol.1, Sih,G.C.(ed.), Noordhoff, Leyden, 1973, Introductory Chapter.

[3] Shioya,T., Fujimoto,K., Trans. Japan Soc. Aero. Space Sci., 25(1983), 246.

[4] Shioya,T., Fujimoto,K., in Mathematical Modeling in Science and Technology, Avula,X.J.R., et al.(eds.), Pergamon Press, New York, 1984, 513.

[5] Griffith,A.A., Phil. Trans. Roy. Soc. London, Ser. A, 221(1921), 163. 